\title{
Modelling a green roof retrofit in the Melbourne Central Business District
}

\author{
S. J. Wilkinson ${ }^{3}$, C. Rose ${ }^{1}$, V. Glenis ${ }^{2}$ \& J. Lamond ${ }^{1}$ \\ ${ }^{I}$ Faculty of Environment and Technology, \\ University of the West of England, UK \\ ${ }^{2}$ The Centre for Earth Systems Engineering Research (CESER), \\ School of Civil Engineering and Geosciences, \\ Newcastle University, UK \\ ${ }^{3}$ School of the Built Environment, University of Technology, Australia
}

\begin{abstract}
With the increasing densification in urban settlements the economic and social disruption caused by pluvial flooding events globally is significant and growing. Furthermore these problems are compounded where many cities are located in areas where climate change predictions are for increased rainfall frequency and/or intensity. One possible solution is the wide scale retrofit with green roof technology as a means of mitigating stormwater runoff in urban settlements. However, it is not known currently where the most effective location for and siting of the retrofitted green roofs in a city or town would be. Moreover, the number of and type of green roof required to reduce pluvial flooding is unknown.

This paper describes a proof of concept framework for an assessment of the potential to reduce pluvial flood hazard through the retrofit of green roofs combining an evaluation of the retrofit potential of office buildings in the Central Business District (CBD) with state-of-the-art urban rainfall inundation modelling. Using retrofit scenarios for Melbourne CBD commercial buildings built between 1998 and 2011 and the rainfall profile of the February 2011 event, the modelled depths of flooding were compared. The results show that the potential to mitigate extreme events via retrofit would be enhanced by consideration of buildings within the wider catchment.

Keywords: flood, green roof, inundation modelling, retrofit, CBD.
\end{abstract}




\section{Introduction}

Globally weather patterns are changing [1], whilst it is not possible to attribute specific extreme events to changing climates there is consensus that the frequency of intense rainfall events is rising and will continue over most land masses, including those where average rainfall is decreasing [1]. Intense rainfall events can cause flash floods, particularly in dense urban areas with low permeability.

For Australia, major flooding occurred over the densely populated East Coast area for two consecutive years from 2010. The State Emergency Service responded to over 100 requests for flood-related damage when a storm caused 29 $\mathrm{mm}$ of rain in half an hour at Perth Airport [2]. In March 2012 the Bureau of Meteorology issued Flood Warnings and broad-scale Severe Weather Warnings for heavy rain and flash flooding over much of northern and eastern Queensland. The estimated costs of remediation of flood damaged buildings is A \$20 billion $[3,4]$.

The incidence of pluvial flooding is, in part, attributable to changing weather patterns, and climate predictions for Australia include increased intense rainfall in south-western and south-eastern Australia [5]. Though there has been a general trend of declining autumn and winter rainfall in south-western and southeastern Australia, Australian average annual rainfall has increased slightly, largely due to increases in spring and summer rainfall, most markedly in north western Australia [5]. Added to this are development pressures and increasing urban density which add to the growth in damage caused by these events [6].

Green roofs have been shown to be highly suitable stormwater controls for retrofitting in dense urban areas [7]. As roofing areas can account for $40-50 \%$ of the impermeable surfaces in urban locations, such modification offers the potential to mitigate pluvial flooding without additional land-take being required [8]. There are two main types of green roof: extensive (incorporating shallow rooted species in a relatively thin substrate) or intensive (deep rooted species found in roof gardens); as the load-bearing capacity of extant structures is a key constraint, the lighter extensive type is generally more appropriate for retrofitting applications. Mitigation of stormwater impacts occur via two processes: water is absorbed by the growing medium, thereby delaying the onset of runoff and attenuating peak flows; the stored water is then released by a combination of evaporation and transpiration, mediated by the foliage [9]. These processes can, therefore, relieve pressure on existing piped drainage systems; in extreme storm events, however, capacity will be exceeded and the design must take this into account [10]. Rose and Lamond's meta-analysis [11] notes that reported performance ranged from $42-90 \%$ of annual rainfall, whilst average retention during storm events varied from $30-100 \%$.

Detailed specific study is, however, needed in order to make the case for retrofitting green roofs: firstly, the surface area and location of candidate roofs within the urban space will have a great influence on the quantity and pattern of runoff attenuated; secondly, a number of physical factors need to be considered in determining retrofit suitability; thirdly, the meteorological conditions 
(including the typical rainfall patterns) and hydrological factors (such as runoff characteristics) both need to be examined. The geographical location of green roofs has, unsurprisingly, an impact on their performance, owing to regional climatic variation: vegetated roofs in a sub-tropical Mediterranean climate [for example, 12] will perform differently from those in a temperate maritime climate such as the UK [13]. Further key factors influencing performance have been found to include roof characteristics such as overshadowing (which can inhibit vegetation growth) and the degree of pitch of the roof [14]; other variables include substrate type; species mix; vegetation height and local weather characteristics (intensity of rainfall; antecedent moisture conditions) [11]. It is also necessary to engage the support of the owners and occupiers of relevant properties, if a retrofitting programme is to be successful; an aid to uptake can be provided via incentive schemes such as those employed in New York City [15] and Portland [16]. Therefore, in this paper, a framework for evaluation of runoff attenuation through retrofit of an urban area is described, with particular reference to a case study in Melbourne Australia.

\section{Approach and data}

The City of Melbourne, Australia, has adopted a policy of attaining carbon neutrality by 2020 [17]; in this context, the aim of adapting 1200 existing commercial buildings to incorporate sustainability was established [18]. A proactive approach to meeting this target has been undertaken, including research to identify suitable properties; it has been established that much of the existing stock in the city is now at the stage where adaptation or retrofit is typically undertaken [19]. In addition, the relevant water company has recommended the adoption of water sensitive urban design for areas where the drainage infrastructure cannot be upgraded [20].

Melbourne is situated on sloping terrain on the banks of the Yarra River, a major watercourse; in common with many major cities, extensive expansion over time has resulted in once-permeable agricultural land on the outskirts being replaced by developments featuring largely impermeable surfaces. Furthermore, tributary watercourses within the Melbourne Central Business District (CBD) have been culverted: not only are culverts prone to collapse and blockages but also, in extreme rainfall events, the volume of water can rapidly exceed the carrying capacity, giving rise to overland flows or 'flash floods'. This was demonstrated in March 2010 when a severe storm resulted in $61 \mathrm{~mm}$ of rain falling on the city in 48 hours, exceeding the average rainfall for the entire month [21]. As a result of this pluvial event, a number of roads were rendered impassable for several hours, a major railway station was flooded and tram services in the area had to be suspended; the foregoing caused severe disruption to the normal functioning of the CBD. The total damage for the storm across the west of the state of Victoria exceeded a billion Australian dollars [22]: severe weather events can, therefore, have serious adverse impacts on the economies of affected areas, with businesses unable to function in the aftermath. 
In the context of anticipated climate change, this region of Australia is predicted to experience more intense storm events: sudden, large volumes of runoff water are, therefore, likely to cause more frequent overland flow responses. Measures to mitigate such events will, therefore, be needed in a major city such as Melbourne.

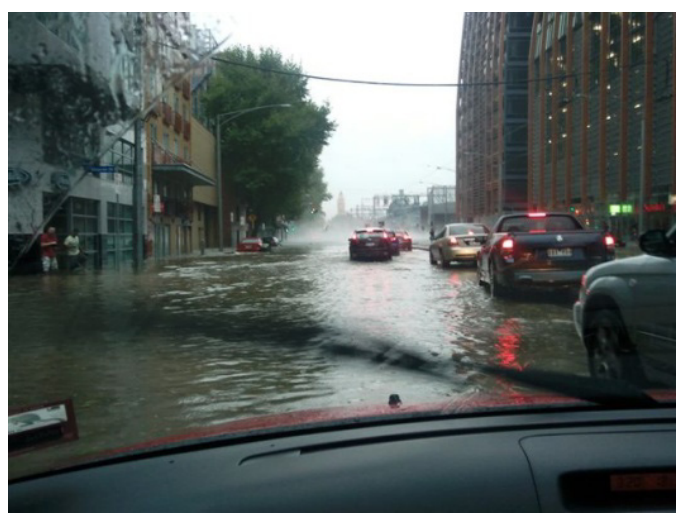

Figure 1: $\quad$ Flash flooding in Flinders Street, Melbourne, 6 March 2010. (Photo courtesy N. Carson.)

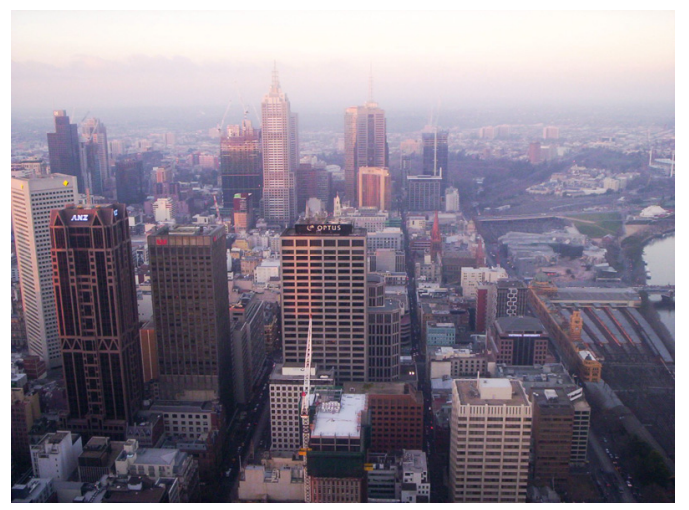

Figure 2: Melbourne CBD showing typical rooftops with Yarra River to right hand side (land generally slopes left to right in this image).

\subsection{Summary of method}

The framework applied to the Melbourne CBD combines assessment of the retrofit potential of the built environment with the application of an inundation model under three retrofit scenarios.

There were three main stages within the framework: 
1. Compilation and analysis of buildings database to evaluate the commercial buildings suitable for retrofit in the Melbourne CBD.

2. Collection and compilation of a digital terrain data for Melbourne and buildings data for the Melbourne CBD.

3. Inundation modelling of the Melbourne CBD area using the rainfall pattern from the flood event of February 2011 under three retrofit scenarios.

This was achieved through the development of a database of commercial buildings within the Melbourne CBD from a variety of sources. The database was compiled using multiple sources, including existing commercial databases such as Cityscope in Australia, and publicly available databases such as PRISM (Victorian Government) and the Heritage database. In addition, data from the Property Council of Australia (PCA), Google Earth and Google Streetview [23] was used to gather building related data. Finally, visual inspections and photographs of CBD buildings were undertaken. Following a comprehensive validation phase the final building database contained 526 commercial buildings in the Melbourne CBD.

The potential for retrofit was evaluated by a qualified building surveyor through visual inspection and using the property database based on the following criteria: Position of the building; location of the building; orientation of the roof; height above ground; roof pitch; weight limitations of the building.

The City of Melbourne Property Services provided contour data for the wider Melbourne catchment was converted to a hydrologically corrected digital terrain model using ARC GIS; shapefile data for buildings, roads and pavement for the CBD were obtained from the same source. The building polygons layer was then modified to create three scenarios: No green roof retrofit, $100 \%$ green roof retrofit and green roof retrofit, for each of the commercial buildings assessed as suitable in stage 1. Rainfall pattern data were purchased from Bureau of Meteorology in Melbourne, and these data were combined within the CityCat rainfall inundation model, as described below.

\subsection{Description of inundation model}

CityCat is an urban flood modelling system based on the shallow water equations [24] capable of modelling pluvial and fluvial flooding in real urban settings. CityCat uses a self-generated grid based on readily available LIDAR Digital Terrain Models and GIS data to represent surface and building characteristics. Areas occupied by buildings are excluded from the numerical grid but buildings are incorporated into the numerical domain as objects and can have different properties/characteristics such as storage on roofs. This is radically superior to other models which represent buildings as raised ground. Surface properties can be altered to predict influences of more permeable surfaces (green-areas) or swales. Simulations of different flood events can be driven by rainfall, flow/water depth time series. 
The architecture of CityCat is based on the object-oriented approach which offers development flexibility and allows easy extension of functionality due to the fully modular structure. Also, the computational efficiency is improved by removing the decisions ("If Then Else" statements) during run time. The solution of the $2 \mathrm{D}$ shallow water equations is obtained using high resolution finitevolume methods with shock-capturing schemes [25] which are able to capture propagation of flood waves. CityCat can also be deployed on the Cloud for high resolution large scale modelling of flooding that can be used for the assessment of city-scale flood risk under climate change [26].

\section{Results}

\subsection{Summary of retrofit potential}

The map of Melbourne CBD (Figure 3) shows the historic centre area known as the 'Hoddle Grid' on the north bank of the Yarra River, in which buildings were assessed for suitability for retrofitting green roofs. Although the CBD is long established the analysis revealed that the majority of the 526 commercial buildings in the database $(60 \%)$ were constructed after 1940 and over half were constructed post 1960 representing a large amount of stock which is potentially due for renewal and upgrade. However, the heights of the buildings are highly variable, with the majority of low to medium rise buildings being mixed in with the approximately $30 \%$ of high rise buildings and skyscrapers. Such an arrangement of buildings could mean that existing buildings which have adequate structural strength to accommodate retrofitting with green roofs may be unsuitable because of overshadowing, which adversely affects planting. However it is possible that consideration of other plant types with substrates designed to be more absorbent than existing specifications might change this finding. Furthermore, the orientation of many of the buildings in the CBD was also seen to be unhelpful to successful plant growth.

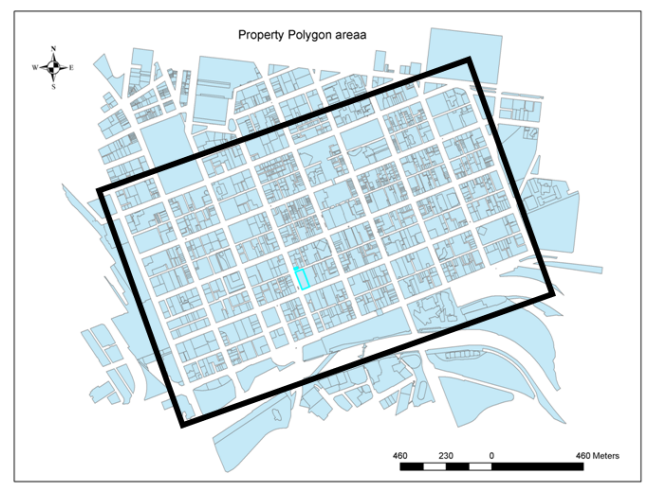

Figure 3: The 'Hoddle Grid' area of Melbourne CBD with the modelled area outlined in black (courtesy N. Bhattacharya-Mis). 
Through visual inspection of the roof, using the Google Earth and Google Map software, an evaluation of individual rooftops was carried out and each roof classified as suitable, not suitable or indeterminate with respect to retrofit potential. This evaluation was based on pitch, roof coverage by service plant and roof construction. From this detailed study it appeared that only $15 \%$ of Melbourne CBD buildings were considered suitable for retrofit; of the remainder, $80 \%$ were seen not to be suitable and $5 \%$ were indeterminate. The database covered only commercial office building stock, however, and many other land use types exist in the $\mathrm{CBD}$, including retail, residential and educational. It is likely that some of the roofs of these buildings would also be suited to retrofit, which would be expected to change the outcome. Finally, it appears that the origin of the body of water which lead to the flooding in the CBD was to the north of, and outside of, the Hoddle Grid and it is logical that consideration of green roof retrofit potential in this stock is undertaken and analysed.

\subsection{Summary of inundation model}

The model outputs are colour-coded to show water depths (as illustrated in Figure 4). The results of the inundation model clearly showed that major flows within the Melbourne CBD during intense storms originate from outside the CBD grid: for example, the route of the Yarra tributary culverted below Elizabeth Street appears here as the white line running on a diagonal from northwest to south-east, entering the main river to the south of the railway station.

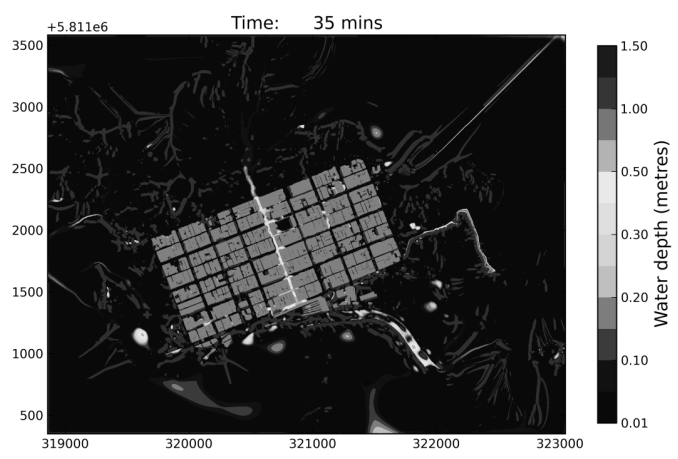

Figure 4: Water depth map - no green roofs (scenario 1).

\subsection{Summary of retrofit model}

A comparison of the modelled outputs reveal that the water depths could be expected to decrease if green roofs were to be retrofitted in the area. In the vicinity of Flinders Street Station, for example (Figure 5) the south-west corner of the road grid has very dark shading (water over 1 metre depth) in scenario 1 
(no green roofs), but this is replaced by a light grey (around 0.5 metre depth) in scenario 3 (suitable roofs retrofitted). The granularity of the comparisons is, of course, more apparent in the full colour images.
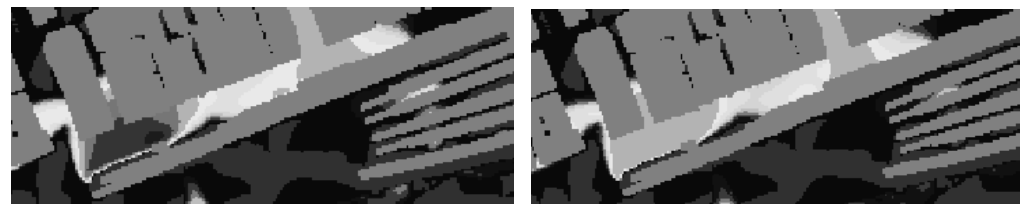

Figure 5: Detail of Flinders Street Station area without green roofs (left) and with green roof retrofit (right).

\subsection{Summary}

The results suggest green roofs offer a potential for mitigation, in that flood levels could be reduced in the affected areas, leading to concomitant reduction in impacts; however, flooding of any depth presents issues for business continuity. The key finding is that the historic flow pathways, normally hidden beneath the urban district, will continue to re-establish their flow patterns during extreme events, directing pluvial flows from the wider catchment towards the Yarra River: in order to mitigate pluvial flooding in the CBD it will, therefore, be necessary to take a wider catchment approach.

\section{Discussion and conclusion}

This paper has presented a framework for the evaluation of green roof retrofit in order to mitigate the impact of extreme rainfall events in business districts. The framework has been applied to an illustrative case study within Australia, namely the city of Melbourne. Novel aspects of this framework include the evaluation of retrofit potential by a qualified building surveyor using an extensive buildings database and the incorporation of a state-of-the-art inundation model that allows precise modelling of inundation within a complex urban environment.

The analysis has demonstrated that such detailed analysis of specific features of the urban environment is very important in achieving a realistic estimate of peak attenuation and resultant flood risk reduction. Within the Melbourne CBD about $15 \%$ of the commercial buildings were seen to be suitable for retrofitting of green roof technology; many of these buildings, however, were concentrated in the sub-prime areas of the business district, rather than the locations known to have experienced the most severe flooding in 2011.

In addition, this inundation model showed that the incorporation of green roofs on all Melbourne's CBD buildings was not sufficient to prevent flooding in extreme rainstorm events. However, some mitigation was observed, in that the depth of flooding at key locations was reduced. When the expert building knowledge was also applied, the potential to mitigate flooding by retrofit within 
the CBD area was greatly reduced, reflecting the fact that high density, prime real estate property is not particularly sympathetic to green roof technology. The implication of this finding for the city of Melbourne is that the potential to mitigate flooding within the CBD solely by using CBD buildings is limited, although other benefits deriving from the use of green roofs and other green infrastructure are well recognised.

The results of the inundation model clearly show that major flows within the Melbourne CBD during intense storms originate from outside the CBD grid. The historic channels that are hidden beneath the urban district re-establish their flow patterns during extreme events, directing pluvial flows from the wider catchment towards the Yarra River: in order to mitigate pluvial flooding in the CBD it will be necessary to take a wider catchment approach.

The potential of the framework to aid in decision making is clearly demonstrated through the case study and therefore it is recommended to widen the scope if the framework to the wider Melbourne area in order to evaluate where the greatest retrofit opportunities exist.

\section{Acknowledgements}

This research was partially funded by the RICS research trust (Project no 464) Retrofit of Sustainable Urban Drainage (SUDS) in CBD for improved flood mitigation

Part of the research was also performed as part of an interdisciplinary project programme undertaken by the Blue-Green Cities Research Consortium (www.bluegreencities.ac.uk). The Consortium is funded by the UK Engineering and Physical Sciences Research Council under grant EP/K013661/1, with additional contributions from the Environment Agency, Rivers Agency (Northern Ireland) and the National Science Foundation.

Thanks are due to the following for data supplied to the project:

Contour and shapefile data: David Hassett, GIS Team Leader, Property

Services, GPO Box 1603, Melbourne, Victoria 3001 Australia

Bureau of Meteorology data: Dr Blair Trewin, National Climate Centre, GPO

Box 1289, Melbourne, Vic 3001, Australia

\section{References}

[1] Solomon, S. and D. Qin, Climate Change 2007: The Physical Science Basis. Contribution of working Group 1 to the Fourth Assessment Report of the Intergovernmental Panel on Climate Change. 2007, Cambridge University Press.: Cambridge, UK and New York, USA.

[2] Bureau of Meteorology. Heavy rain and Flooding. 2012 9th July 2012; Available from: http://www.bom.gov.au/wa/sevwx/perth/floods.shtml.

[3] Bloomberg (2012) Insurers count cost in Queensland as floods peak.

[4] Companies and Markets (2011) Australian Flood Damage Reconstruction Likely to Cost Billions. 
[5] Bureau of Meteorology. 2014; Available from: http://www.bom.gov.au /climate/change/.

[6] Jha, A., et al., Five Feet High and Rising - Cities and Flooding in the 21st Century, in Policy Research Working Paper 5648. 2011, The World Bank: Washington.

[7] Voyde, E., E. Fassman, and R. Simcock, Hydrology of an extensive living roof under sub-tropical climate conditions in Auckland, New Zealand. Journal of Hydrology, 2010. 394(3-4): pp. 384-395.

[8] Stovin, V., The potential of green roofs to manage Urban Stormwater. Water and Environment Journal, 2010. 24(3): pp. 192-199.

[9] Mentens, J., D. Raes, and M. Hermy, Green roofs as a tool for solving the rainwater runoff problem in the urbanized 21st century? Landscape and Urban Planning, 2006. 77(3): pp. 217-226.

[10] Balmforth, D., et al., Designing for exceedance in urban drainage - good practice CIRIA C635 2006, CIRIA.

[11] Rose, C.B. and J. Lamond, Performance of sustainable drainage for urban flood control, lessons from Europe and Asia, in International Conference on Flood Resilience - Experiences in Asia and Europe, D. Butler and S. Djordjevic, Editors. 2013: Exeter, United Kingdom.

[12] Fioretti, R., et al., Green roof energy and water related performance in the Mediterranean climate. Building and Environment, 2010. 45(8): pp. 1890-1904.

[13] MacIvor, J.S. and J. Lundholm, Performance evaluation of native plants suited to extensive green roof conditions in a maritime climate. Ecological Engineering, 2011. 37(3): pp. 407-417.

[14] Wilkinson, S.J. and R. Reed, Green roof retrofit potential in the central business district. Property Management, 2009. 27(5): pp. 284-301.

[15] Bloomberg, M.R. and C.H. Strickland, NYC Green Infrastructure - 2012 Annual Report. 2012, New York City - Envirionmental Protection: New York City.

[16] Environmental Services - City of Portland. Portland's Ecoroof Program 2011, cited 2013; Available from: http://www.portlandoregon.gov/bes /article/261074.

[17] Arup Pty Ltd, Zero Net Emissions by 2020 - update 2008 (Consultation Draft). 2008, City of Melbourne.

[18] Maunsell Australia Pty Ltd, Towards a City of Melbourne Climate Change Adaptation Strategy: A Risk Assessment and Action Plan Discussion Paper Responding with Resilience. 2008, City of Melbourne, Australia.

[19] Jones Lang LaSalle, Building Refurbishment - Repositioning your asset for success. 2005, Jones Lang LaSalle: Melbourne, Australia.

[20] Melbourne Water Corporation, Flood Management and Drainage Strategy. 2007, Melbourne Water Corporation.

[21] The Telegraph. Super storm and giant hailstones lash Melbourne. 201008 March 2010, cited 2014; Available from: http://www.telegraph.co.uk /news/worldnews/australiaandthepacific/australia/7394608/Super-stormand-giant-hailstones-lash-Melbourne.html. 
[22] Insurance Council of Australia. Historical disaster statistics, cited 2014; Available from: http://www.insurancecouncil.com.au/industry-statisticsdata/disaster-statistics/historical-disaster-statistics.

[23] Google Maps. no date; Available from: www.google.com.au/maps.

[24] Weiyan, T., Shallow water hydrodynamics. Elsevier Oceanography Series, 1992. 55: p. 434.

[25] Toro, E., Riemann solvers and numerical methods for fluid dynamics. Third ed. 2009, Berlin Heidelberg: Springer-Verlag. p. 724.

[26] Glenis, V., et al., Flood modelling for cities using Cloud computing. Journal of Cloud Computing: Advances, Systems and Applications, 2013. 2(7). 